\title{
FACTORS THAT MOTIVATE OR OBSTACLE THE IMPLEMENTATION OF ENVIRONMENTAL EDUCATION IN THE CONTEXT OF SPECIAL EDUCATION: OPINIONS OF GENERAL AND SPECIAL EDUCATION TEACHERS
}

\author{
Dr. Loukas Moustakas ${ }^{1}$ and Phaedra Mania ${ }^{2}$ (1) \\ ${ }^{1}$ Postdoctoral researcher and lecturer at the MSc program "New Forms of Education and Learning" of the Department of \\ Preschool Education and Educational Design of the School of Humanities of the University of the Aegean, Greece \\ ${ }^{2}$ M.Sc., M.Ed.,, Graduate of the MFA program "Environmental Education" of the Department of Preschool Education and \\ Educational Planning and the MFA program "Models of Intervention in Special Education" of the Pedagogical Department \\ of Primary Education of the University of the Aegean, Greece
}

Received 4 July 2021

Accepted 24 July 2021

Published 31 July 2021

Corresponding Author

Dr. Loukas Moustakas, lmoustakas

@rhodes.aegean.gr

DOI 10.29121/

granthaalayah.v9.i7.2021.4133

Funding: This research received no specific grant from any funding agency in the public, commercial, or not-for-profit sectors.

Copyright: (C) 2021 The Author(s). This is an open access article distributed under the terms of the Creative Commons Attribution License, which permits unrestricted use, distribution, and reproduction in any medium, provided the original author and source are credited.

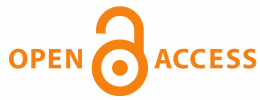

\section{ABSTRACT}

The present study attempts to investigate the views of general and special education teachers regarding those factors that motivate and hinder the implementation of Environmental Education (E.E.) in the context of Special Education (S.E.). It is a quantitative research for the needs of which a questionnaire was created based on the theoretical framework of the study in order to be given to teachers on the island of Rhodes. From the analysis of the results it was found that the main factors that can motivate the implementation of the E.E. in the context of S.E. is the willingness of teachers to implement innovative programs (such as E.E.), the benefits arising from the implementation of E.E. to the students with special educational needs and/or disabilities, the personal interest of the teachers in E.E., their environmental education, the acquisition of knowledge about environmental issues and the adequate training of the teachers in subjects of P. E. and E.A. On the other hand, the most important factors that can hinder its implementation are the lack of time/inflexibility of the program, the bureaucratic process for the approval of the program, the lack of material and technical equipment, the lack of training of teachers in the subject of E.E. and the workload of teachers.

Keywords: Supporting Factors, Inhibiting Factors, Application, Environmental Education, Special Education, Views, Teachers

\section{INTRODUCTION}

The relationship between Environmental Education (E.E.) and Special Education (S.E.) has been the subject of much research with the ultimate goal of exploring 
whether E.E. can to be applied to students with special educational needs and/or disabilities and if it can contribute to their development and education. Results of research showed that E.E. can be applied in S.E., as there are common goals that focus on creating a society based on equality, democracy and the active participation of all citizens in the issues of everyday life. However, in order for E.E. to exist in the context of S.E. In schools, the curriculum should be modified and the school should acquire a new philosophy which will be based on the principles and values of these two fields. In this direction, teachers are called to make changes in school environments, so that the programs of E.E. can be effective and beneficial for these students Boutskou (2006). With the application of E.E. in S.E., students have the opportunity through the investigation of various factors to become aware of environmental issues, to acquire skills to adapt to the social environment, to work together to solve problems and to develop comprehensively. Methods used during E.E., such as active and experiential learning, individual participation, collaborative teaching, role-playing, group dynamics, encouragement, experimentation and exploration contribute to this direction by offering a variety of stimuli and experiences in students with special educational needs and/or disabilities. Research has shown that in the context of S.E., E.E. can play a dual role. On the one hand it can sensitize and educate people about the protection of the environment and the principles of sustainability and on the other hand it is an important means of education Papageorgiou et al. (2015).

A well-structured program of E.E. or a well-organized environmental action can provide a multi-sensory environment, full of images, sounds, tastes, aromas and objects, enabling students with special educational needs and/or disabilities, depending on the type of disability they have, to learn. After all, it has been found to be scientifically suitable for special education, mainly due to the fact that it can improve the difficulties they may face in memory, attention and perception. Furthermore, it has been shown that environmental activities and programs can offer students leisure and cultural activities and display similar behaviors, while at the same time increase positive stimuli and improve social contact between individuals. The participation of students in outdoor activities can make a decisive contribution to the cognitive, interpersonal and individual development of the individual, such as the strengthening self-confidence, the feeling of happiness, the increase of self-esteem, but also to their decision-making, critical thinking and taking initiatives skills Bryant et al. (1995), Siperstein et al. (2007), Varnava et al. (2009).

The bibliography states that the goals of E.E. can operate in addition to those of S.E. and be combined, as students with or without special educational needs and/or disabilities are given the opportunity to benefit from experiential learning opportunities and improve their quality of life. Students through these programs gain unique experiential experiences, internalize the environment through tools and methodological approaches that arouse their interest. In fact, the supplies specifically acquired by students with special educational needs and/or disabilities make them active recipients who can jointly shape the terms and conditions of their lives. 
The principles of solidarity, tolerance, autonomy and responsibility embraced by both E.E. and S.E. create the appropriate environment to promote the coeducation of all students Varnava et al. (2009), Papanis et al. (2007).

Therefore, it is important to investigate those factors that motivate, but also those that hinder the implementation of E.E. in the context of S.E. in order for it to be able to be applied effectively at all levels of education, offering a variety of benefits to students with or without special educational needs and/or disabilities.

Inhibitory factors regarding the application of E.E.

In the international literature one of the elements that are investigated from time to time regarding E.E. are those obstacles or factors that make it difficult to apply in the educational process, mainly in an attempt to identify the gaps that exist between environmental concern and the action or behavior of individuals Blake (2007), Kollmuss and Agyeman (2010). Most of the research that has been conducted in developed countries, such as the USA, the United Kingdom, Canada and Australia, focuses on factors related to teacher training, curricula, financial constraints and security issues Monroe et al. (2002), Ernst (2007). Similar research that has been conducted in less developed countries, such as China, has shown that barriers to community and government support, lack of time, materials and funding are seen as obstacles Lee et al. (2009). In Latin America, research focuses on material barriers, such as lack of teaching time, preparation and training materials, but also other barriers, such as lack of natural environment, curriculum issues, lack of subject knowledge, teachers' low self-esteem and lack of comfort outdoors Penwell et al. (2002), Cronin-Jones et al. (2003),

Furthermore, González-Gaudiano Gonzalez-Gaudiano (2007) mentions as obstacles in his research the management/direction of the school, the lower position of E.E. in the curriculum and teacher training (e.g. issues related to dependence on traditional teaching methods, learning strategies used, the difference between theory and practice, lack of ongoing support, etc.). In developing countries, barriers seem to focus more on local environmental and socio-economic contexts Gray (1999), Campbell et al. (2010), Anderson and Jacobson (2018).

At the same time, Rickinson et al. Rickinson et al. (2004) identified in their research five main obstacles related to E.E. and outdoor activities. First of all, there is a strong concern for student safety and the legal liability associated with potential risks. A second obstacle is teachers' self-confidence and the degree of experience they have in such matters, which seems to influence both their choices about what they teach, but much more about how they will teach the subject and how well they will do it. Another major obstacle is the requirements of the curriculum at regional, state and national level. In fact, many educators often have no choice in the subject they will teach because of these political instructions. Another category is physical barriers, such as time, resources and support. The last category includes obstacles, such as the teacher-student ratio, the organization/structure of the courses, the daily school curriculum and the school budget Adams (2013). According to Kim and 
Fortner Kim and Fortner (2006) barriers can be divided into two broad categories, internal and external. In their research they point out that often the obstacles that are observed are directly related to the environmental issue that they are negotiating. For example, if an issue is not presented extensively in the books, this in itself is an obstacle to that issue. Regarding the internal obstacles, they are connected with the respective teacher. Such inhibiting factors can be the attitudes, values, beliefs and experiences of teachers, but also their abilities on a cognitive and pedagogical level. External barriers, which are beyond the influence of teachers, address issues that affect learning and teaching, such as responsibility, school curriculum, funding, resources and lack of time Rickinson et al. (2004), Simmons (1998), Dyment (2005).

In similar surveys conducted in Greece in the field of S.E., it has been found that not many E.E. programs are implemented, mainly in special schools due to the fact that teachers do not have the appropriate training in environmental issues, they are not confident and do not know how to implement such an innovative program, they are worried about the teaching methods that should be used (ignorance of designing methodology, they felt insecure about their pedagogical ability), the staff in the schools is often not consistent (existence of many substitute teachers, secondments and transfers of teachers), there was no coherence with the school philosophy and priority was given to more "basic" issues, such as a common code of communication, teaching of students to learn to read, write and count. At the same time, the teachers, in addition to their concerns about the methodology and implementation of such a program, were concerned about the outcome of the program and its effectiveness. Furthermore, the possible lack of discipline in the classroom, the usefulness of the program in educating children, the opinion/criticism of other colleagues and/or parents (e.g. if they did anything in the yard they would possibly think that they were avoiding teaching), but also the lack of cooperation of teachers were some of their concerns Boutskou (2006). One of the most important factors that can prevent the implementation of E.E. in S.E., as characteristically stated by Giannopoulou and Kazakou Giannopoulou and Kazakou (2010) in their research, is the nature of the difficulties faced by students with special educational needs and/or disabilities and the degree of severity of the difficulties of each student individually.

In this direction, Floridis Floridis (2010) in his research comes to agree with previous research, since he points out that one of the main inhibiting factors for the implementation of E.E. in S.E. are issues related to student safety, especially when it is implemented outside the classroom. What he argues is that any movement of students with special educational needs and/or disabilities, involves risks that teacher must anticipate when planning environmental actions. This should be preceded by a detailed discussion with the students about what will follow, while at the same time teachers should have increased awareness and prevention skills that would help them with the potential dangers, even the most unlikely dangers that may arise. In a research conducted by Lappa, Kyparissos and Paraskevopoulos in Greece on teachers of S.E. regarding the implementation of E.E., the results showed that most teachers do 
not feel ready to teach E.E. to students with special educational needs and/or disabilities due to the fact that they do not have appropriate education or sufficient knowledge about the way of teaching E.E. to these children and should therefore receive further education on activities that provide ideas for planning such a course, as well as on the various disabilities. At the same time, the lack of a historical background of the implementation of E.E. in S.E. in Greece, but also the perception that E.E. cannot be easily implemented in children with multiple disabilities are considered two of the main obstacles in its implementation in the context of S.E. Moreover, the fact that there is no official policy for E.E. in special schools in the curriculums, makes its application even more difficult Lappa et al. (2017).

Supporting factors for the implementation of the E.E.

In a study conducted by Ardoin, Bowers and Gaillard Ardoin et al. (2020) on the results of the implementation of E.E. in schools, it has been found that factors such as the acquisition of knowledge, the development of social, emotional and academic skills, motivation and socio-"political" action and interest can enhance the implementation of such actions in schools. Results of other research Ko et al. (2003), Ekborg (2003) report, as important reinforcing factors, the positive attitudes of teachers towards the environment, since it has been found that those who have environmental education carry out more environmental actions and programs in their classroom. In this direction, Sadik and Sadik Sadik and Sadik (2014) come to confirm in their research that the implementation of E.E. is directly related to the environmental education, attitude and habits of teachers.

At the same time, in a research conducted by Muranen Muranen (2014) on which factors enhance the application of E.E. in schools, he referred to both school-related factors (internal factors) and factors that focus on the wider society (external factors). In particular, in regards to external factors, it has been established that an important role for the implementation of E.E. is the support of the school board, the contribution of the society to the environmental awareness of its citizens, the local authorities and the financing of such programs, the development of the area where the school is located and the policy pursued by the government. As for the internal factors that refer to the school itself, they focus on the philosophy and organizational culture that the school follows, i.e. whether it designs and implements innovative programs for the education of students, the values and principles that the school embraces through its administration, but also on the perceptions, attitudes and beliefs of teachers and the principal on environmental issues.

It is also argued that the cooperation between teachers of all specialties is equally important for the implementation of E.E. programs, since it has been proven that teachers who show interest and are willing to work with their colleagues, are the ones who carry out the most often such actions in schools Ballantyne and Packer (2006). In addition, it has been found that determining factors for the implementation of E.E. in schools are the very benefits that students receive from participating in them. More specifically, research has shown that a person's contact with nature and the 
environment contributes to their emotional, social and cognitive development, while at the same time they develop skills, values and attitudes that lead to a responsible environmental behavior and environmental ethics Kellert (2005), Chawla (2006).

Research conducted in the field of outdoor education and its integration into the design of E.E. curricula, it was found that learning about environmental management and how to care for nature has positive effects on the way students themselves deal with themselves and others (Wilson, 1994, Dominguez \& Schilling, 2001, Berger, 2006). In fact, the same research argues that the skills acquired during learning to care for the environment contribute positively to other difficulties faced by most students with special educational needs and/or disabilities, such as low self-esteem and learning weaknessese Dominguez and Schilling (2001), Berger (2006). At the same time, students who experience emotional and behavioral difficulties and took part in outdoor activities appeared to acquire more positive attitudes toward school and their effective integration into it Berger (2006), Shiderman (2016).

In this direction, results of research on the implementation of E.E. in S.E. showed that students with special educational needs and/or disabilities by participating in such activities enhance the development of basic skills, such as communication, collaboration, reading ability, comprehension of mathematical concepts, listening, visual perception, logical-mathematical thinking and reasoning, while at the same time significantly improve in terms of general knowledge, social interaction, interest and attitudes Scruggs and Mastropieri (1995). In a multi-year research conducted by Boutskou, she found that although initially the teachers in special schools were reluctant to implement E.E. programs, then when they realized the benefits that arise, they decided to participate in such actions in the following years. This shows that the effectiveness of the program itself and the training of teachers in the design and implementation of the programs acted as a supporting factor. In fact, following the whole process last year, from the design to the implementation of such a program, the teachers felt ready and confident in themselves to implement the programs themselves Boutskou (2006).

\section{MATERIALS AND METHODS}

Object of research: The present research is part of the field of education and more specifically of the design, implementation and application of innovative educational programs that can be integrated in the field of special education. In this direction, E.E. is an educational process that can be utilized in S.E. using appropriate methods, techniques, teaching approaches and strategies. It is therefore interesting to investigate the implementation of E.E. programs or environmental actions to students with special educational needs and/or disabilities in both general and special education schools, but also those factors that motivate and hinder its implementation. Therefore, this research attempts to contribute to the enrichment of the discussion related to the implementation of E.E. in S.E. focusing on those factors that contribute deci- 
sively to its implementation, wanting in this way to record on the one hand the problems that arise and those elements that hinder the implementation, and on the other hand those factors that act as an incentive for its implementation, in order to emerge and support the development of corresponding environmental actions within the S.E.

Research methodology: It is worth mentioning that in order to carry out any research, the purpose and objectives must first be defined, which in turn largely determine the methodology that will be used to conduct it Creswell (2016), Robson (2010). The present research is a quantitative research, which uses the questionnaire as a methodological tool. In fact, due to the prevailing conditions nowadays, an electronic questionnaire was created through google forms, in order to be distributed digitally to the participants. The questionnaire consists of two main parts, the demographic data and the general survey questions which are divided into four axes. The survey was conducted in March and April of 2021 on the island of Rhodes and the questionnaires were distributed electronically to the participating teachers. The questionnaire was created based on the theoretical framework developed for this study and was based on the goals and objectives that were initially set. After completing and collecting the questionnaires, the data were analyzed with the ultimate goal of extracting the results of the research. Initially, an excel file was exported from google forms, in order to be edited and coded properly, so that it could be included in the S.P.S.S. statistical package for the statistical processing and analysis of the research data.

Reference population and research sample: In the present research the views of general and special education teachers are investigated. More specifically, the reference population is defined as the teachers who serve in schools on the island of Rhodes and can work as general class teachers or as special education teachers (e.g. parallel support, in an integration department or in a special education school unit). Due to the conditions prevailing in the specific time period, the research involved as many teachers as possible from the schools of Rhodes, since the questionnaire was in electronic form and was sent to the address of the respective school that forwarded it to its teachers. As a final sample of the research, 190 teachers participated in this process, of which 136 were women $(71.6 \%)$ and 54 men (28.4\%). In terms of age, $38.9 \%$ belong to the age group "20-30" years old, $29.5 \%$ to the age group "31-40" years old, $20.0 \%$ " $41-50$ " years old, while $11.6 \%$ are over 51 years old. In terms of years of service, $64.2 \%$ have " $0-10$ " years, $21.1 \%$ "11-20", 11.1\% "21-30", while only $3.7 \%$ have over from 31 years of service. Regarding the specialty of the teachers of the sample, $54.7 \%$ are general class teachers, $24.7 \%$ are parallel support teachers, $6.8 \%$ are teachers in the integration department and $13.7 \%$ are teachers in a special education school unit. Finally, in terms of advanced education/specialization that teachers have, $60.0 \%$ are specialized in Special Education, $10.0 \%$ in Environmental Education, 7.4\% are specialized in both Special Education and Environmental Education, while $22.6 \%$ are specialized in a different subject. 
Regarding the reliability and validity of the research, all the necessary steps have been taken for them to be established. During the regularity check of all values it was found that none of the variables' value follow the normal distribution (KolmogorovSmirnov $\mathrm{p} \leq .050$ ), so in the context of the correlation analysis, non-parametric criteria are used. More specifically, in the case where there is an independent categorical variable of two categories (e.g. gender) and a dependent variable on a likert scale (e.g. "To what extent do you think that the following factors motivate the application of E.E. in the context of S.E.?") the non-parametric Mann-Whitney U test was used instead of the t-test for independent samples. While in the case that there is an independent categorical variable of more than two categories (e.g. age group) and a dependent variable on a likert scale, (e.g. "To what extent do you think that the following factors hinder the application of E.E. in the context of S.E.;"), the non-parametric KruskalWallis $\mathrm{H}$ test was used instead of the parametric One-way ANOVA. Because the nonparametric criteria in the calculation convert the values of the gradient variables (likert) into ordinal (1st, 2nd, 3rd, etc.) and therefore do not give in the descriptive results of the criteria the averages and the standard deviations, the central tendency and scatter indexes were selected to be extracted from the respective parameters. At this point it should also be mentioned that for all cases of statistical control, the level of statistical significance is set to $p=.050$. As part of the analysis, the Cronbach Alpha index was checked, which in all cases (except two cases) was above .700 which is considered to be a high level of internal consistency. So overall the tools used are judged by high internal coherence Moustakas and Fokiali (2019).

\section{RESULTS AND DISCUSSIONS}

Teachers' views regarding the implementation of E.E. in the context of S.E.: The second axis of the questionnaire issued to teachers refers to the implementation of E.E. in S.E. and consists of five grading questions to explore their views on it. The fourth question of the questionnaire refers to the supporting factors regarding the application of E.E., while the fifth question concerns the inhibitory factors of the application. In particular, the results of the research showed that:

Regarding the supporting factors: $91.6 \%$ of the sample considers as the most important supporting factor the "willingness of the teachers to implement innovative programs, such as E.E." (the average of the degree of agreement is 4.42) and 93.1\% the "benefits arising from the implementation of E.E. into students with special educational needs and/or disabilities" (the average of the degree of agreement is 4.42). Equally important factors for teachers are the "personal interest of teachers in E.E." at a rate of $90.0 \%$ (the average of the degree of agreement is 4.40 ), the "environmental education of teachers" at a rate of $89.0 \%$ (the average of the degree of agreement is 4.31), the "acquisition of knowledge" at $89.4 \%$ (the average of the degree of agreement is 4.26), the "appropriate logistics" at $86.4 \%$ (the average of the degree of agreement is 4.25 ) and the "adequate training of teachers in matters of E.E. and 
S.E." at $87.4 \%$ (the average of the degree of agreement is 4.25 ). In addition, $80.5 \%$ referred to the "existence of cooperation between teachers and management" (the average of the agreement is 4.20 ), $83.7 \%$ to the "simplification of bureaucratic procedures (e.g. the process of submitting a program plan)" (the average of the degree of agreement is 4.19 ) and $84.2 \%$ in the "existence of cooperation with local bodies for the elaboration of E.E. programs" (the average of the degree of agreement is 4.18). At the same time, important supporting factors according to the teachers are the "existence of cooperation of teachers with each other" at a rate of $83.7 \%$ (the average of the degree of agreement is 4.17), the "philosophy of the school unit/organizational culture (development of innovative programs)" at 85.8\% (the average of the degree of agreement is 4.17), the "financial support - financing of programs" at 78.5\% (the average of the degree of agreement is 4.09) and the "appropriate building infrastructure" at $74.8 \%$ (the average of the degree of agreement is 3.96 ).

Regarding the inhibitory factors: $80.0 \%$ of the sample considers as the most important inhibitory factor the "lack of time (due to the pressure of the Curriculum)/inelasticity of the program" (the average of the degree of agreement is 4.08). $76.3 \%$ report the "bureaucratic procedure for the approval of the program" (the average of the degree of agreement is 4.04) and the "lack of logistics" (the average of the degree of agreement is 4.03), while 77.3\% note the "lack of training (lack of knowledge) of teachers in the subject of E.E." (the average of the degree of agreement is 4.00). Equally important factors for teachers are the "personal reasons of teachers (e.g. they do not feel that they can deal with this subject)" at a rate of $72.1 \%$ (the average of the degree of agreement is 3.93), the "workload of teachers" at a rate of $72.7 \%$ (the average of the degree of agreement is 3.93), the "difficulties in the organization of the program (planning, coordination, implementation)" at a rate of $75.8 \%$ (the average of the degree of agreement is 3.92) and the "school culture/philosophy" at a percentage of $71.6 \%$ (the average of the degree of agreement is 3.91). In addition, $69.5 \%$ referred to "inadequate building infrastructure" (the average of the degree of agreement is 3.88), $72.1 \%$ to "diversity (range) of difficulties/disabilities faced by students" (the average of the degree of agreement is 3.87), $67.9 \%$ in the fact that "there is no funding" (the average of the degree of agreement is 3.87), 71.0\% in the "difficulties in the movement of students" (the average of the degree of agreement is 3.86 ) and $68.9 \%$ in the" differentiation of the material that will be used for the difficulties of each student" (the average of the degree of agreement is 3.82 ). At the same time, important inhibitory factors according to the teachers are the "non-support of the school management" at a percentage of $61.6 \%$ (the average of the degree of agreement is 3.73), the "lack of cooperation of teachers of different specialties" at a percentage of $60.0 \%$ (the average of the degree of agreement is 3.68), the "lack of cooperation with parents/non-parental support" at $61.1 \%$ (the average of the degree of agreement is 3.68), the fact that "E.E. is not in the interests of teachers" at a rate of $59.5 \%$ (the average of the degree of agreement is 3.64) and the "non-support of the local directorate of education" at a rate of $61.6 \%$ (the average of the degree of 
agreement is 3.63). Finally, to a lesser extent inhibitory factors constitute the "noncorrelation of E.E. with S.E. (teachers consider that E.E. cannot be taught to children with special educational needs and/or disabilities)" at a rate of 53.2\% (the average of the degree of agreement is 3.47), the "fear of failure implementation of such programs" at a rate of $45.8 \%$ (the average of the degree of agreement is 3.38 ) and the "attitudes of the students themselves" at a rate of $50.0 \%$ (the average of the degree of agreement is 3.34).

Differentiation of teachers' views regarding their gender in regards to the supporting factors: The results of the research showed that there is a statistically significant difference in 6 of the 14 supporting factors. More specifically, women believe to a greater extent than men that those factors that can act as supporting in the implementation of E.E. in the context of S.E. are the "personal interest of teachers in E.E." [women averaged at 4.52/men averaged at $4.09(\mathrm{U}=2509,500, \mathrm{p}=.000)$ ], the "availability of teachers to implement innovative programs, such as E.E." [women averaged at $4.50 / \mathrm{men}$ averaged at $4.20(\mathrm{U}=2872,000, \mathrm{p}=.009)]$ and the "appropriate logistics" [women averaged at 4.33/men averaged at $4.06(U=2988,000, p=.029)$ ]. Equally important are the "appropriate building infrastructure" [women averaged at $4.03 /$ men averaged at $3.78(\mathrm{U}=3029,000, \mathrm{p}=.048)]$, the "philosophy of the school unit/organizational culture (development of innovative programs)" [women averaged at $4.25 /$ men averaged at $3.98(\mathrm{U}=2884,500, \mathrm{p}=.011)]$ and the "benefits arising from the application of E.E. to students with special educational needs and/or disabilities" [women averaged at $4.51 /$ men averaged at $4.17(\mathrm{U}=2651,500, \mathrm{p}=.001)$ ].

Differentiation of teachers' views regarding their gender in regards to the inhibitory factors: The results of the research showed that there is a statistically significant difference in 8 out of the 21 inhibitory factors given. More specifically, women believe to a greater extent than men that those factors that can act as inhibitory to the implementation of E.E. in the context of S.E. are the "personal reasons of teachers (e.g. they do not feel that they can deal with this subject)" [women averaged at 4.04/men averaged at $3.65(\mathrm{U}=2737,000, \mathrm{p}=.003)]$, the "fear of failure to implement such programs" [women averaged at 3.52/men averaged at 3.02 (U= $2599,500, p=.001)]$, the "non-correlation of E.E. with S.E. (teachers consider that E.E. cannot be taught to children with special educational needs and/or disabilities)" [women averaged at 3.59/men averaged at $3.19(\mathrm{U}=2934,000, \mathrm{p}=.025)$ ] and the fact that "there is no funding" [women averaged at 3.97/men averaged at 3.63 (U= $2990,000, p=.036)]$. Equally important are the "lack of logistics" [women averaged at $4.12 /$ men averaged at $3.81(U=2990,000, p=.033)]$, the "school culture/philosophy" [women averaged at 3.99/men averaged at $3.70(\mathrm{U}=2945,500, \mathrm{p}=.022)$ ], the "differentiation of the material that will be used for the difficulties of each student" [women averaged at 3.91/men averaged at $3.59(\mathrm{U}=2928,000, \mathrm{p}=.019)$ ] and the "attitudes of the students themselves" [women averaged at 3.48 / men averaged at $2.98(\mathrm{U}=2692,500, \mathrm{p}=.003)]$. 


\section{CONCLUSIONS AND RECOMMENDATIONS}

In general, the results of the research showed that with regard to the supporting factors, the teachers mentioned to a high degree, factors such as the willingness of the teachers to implement innovative programs, the benefits that result from the implementation of E.E. to the students with special educational needs and/or disabilities, the personal interest of the teachers in E.E., their environmental education, the acquisition of knowledge about environmental issues, the adequate training of the teachers in the subjects of E.E. and S.E., the appropriate material and technical equipment, the existence of cooperation between teachers and management, the simplification of bureaucratic procedures (e.g. process of submitting a program plan), the existence of cooperation with local bodies for the elaboration of E.E. programs and the cooperation between the teachers themselves, the philosophy of the school unit/organizational culture (development of innovative programs), the financial support financing of programs, but also the appropriate building infrastructures.

On the other hand, regarding the inhibitory factors, the teachers mainly mentioned the lack of time (due to the pressure of the curriculum)/inelasticity of the program, the bureaucratic procedure for the approval of the program, the lack of material equipment, the lack of training (lack of knowledge) of teachers in the subject of E.E., the personal reasons of the teachers (e.g. they do not feel that they can deal with this subject, the workload, the difficulties in the organization of the program (planning, coordination, implementation), the school culture/philosophy, the inadequate building infrastructure, the diversity (range) of difficulties/disabilities faced by students, the fact that there is no funding, the difficulties in moving students and the diversification of material that need to be used based on the disability of each student. At the same time, they noted factors such as the lack of support from the school, the lack of cooperation of specialties, the lack of cooperation with parents/non-support of parents, the fact that the E.E. is not in the interests of teachers, the non-support of the local directorate of education, the non-correlation of E.E. with S.E. (teachers believe that E.E. cannot be taught to children with special educational needs and/or disabilities), the fear of failure to implement such programs and the attitudes of the students themselves.

From the results of the present research, but also of other corresponding researches that have been carried out at international level, it results that the application of E.E. in schools in any context is supported by factors such as the teacher training in environmental issues and the design of such programs, the teachers' attitudes, perceptions and beliefs about environmental issues, the teachers' mood and personal interest in dealing with something new, the philosophy and value system adopted by the school, the school culture, the simplification of bureaucratic procedures (e.g. program submission process, student relocation), the existence of appropriate logistical infrastructure and supervisory means, the economic support-funding of such programs by local agencies, the cooperation of teachers with each other and with the principal, as well as the benefits for the 
students. On the other hand, the application of E.E. in schools can be hindered by factors such as the rigidity/inelasticity of curricula, time pressure, the use of new forms of teaching methodology, the lack of teaching materials and supervisory tools, the lack of material infrastructure of schools, the lack of funding for curricula, the bureaucracy, the difficulty in the movement of the students, the organization and the planning of the program, the insufficient training of the teachers and the negative attitudes of the teachers towards the institution of E.E.

\section{REFERENCES}

Adams, T. R. (2013). Overcoming Barriers To Teaching Action-Based Environmental Education: A Multiple Case Study Of Teachers In The Public School Classroom. [Masters Theses \& Specialist Projects]. The Faculty Of The Department Of Educational Administration, Leadership \& Research. Bowling Green, Kentucky: Western Kentucky University.

Anderson, C., \& Jacobson, S. (2018). Barriers To Environmental Education: How Do Teachers' Perceptions In Rural Ecuador Fit Into A Global Analysis. Environmental Education Research, 24, 1684-1696.

Ardoin, N. M., Bowers, A. W., \& Gaillard, E. (2020). Environmental Education Outcomes For Conversation: A Systematic Review. Biological Conservation, 108224-108224.

Ballantyne, R., \& Packer, J. (2006). Promoting Learning For Sustainability: Principals' Perceptions Of The Role Of Outdoor And Environmental Education Centers. Australian Journal Of Environmental Education, 22(1), 15-29.

Berger, R. (2006). Using Contact With Nature. Creativity And Rituals As A Therapeutic Medium With Children With Learning Difficulties: A Case Study. Emotional And Behavioural Difficulties, 11(2), 135-146.

Blake, J. (2007). Overcoming The Value-Action Gap. Environmental Policy: Tensions Between National Policy And Local Experience. Local Environment, 4(3), 257-278.

Boutskou, E. (2006). Environmental And Special Education: Emerging Concerns. Presentation Presented At The 2nd Conference Of School Programs Of Environmental Education, December 15-17. (pp. 490-495). Athens.

Bryant, J. A., Banta, T. W., \& Bradley, J. L. (1995). Assessment Provides Insight Into The Impact And Effectiveness Of Campus Recreation Programs. NASPA Journal, 32(2), 153-160.

Campbell, T., Medina-Jerez, W., Erdogan, I., \& Zhang, D. (2010). Exploring Science Teachers' Attitudes And Knowledge About Environmental Education In Three International Teaching Communities. International Journal of Environmental And Science Education, $5(1), 3-29$.

Chawla, L. (2006). Learning To Love The Natural World Enough To Protect It. Barn, 2, 57-78.

Creswell, W. J. (2016). Research In Education. Design, Conduct And Evaluation Of Quantitative And Qualitative Research (Ch. Tsorbatzoudis, Ed. \& N. Kouvarakou, Translated). Athens: Ion.

Cronin-Jones, L., Penwell, R., Hakverdi, M., Cline, S., Johnson, C., \& Scales, I. (2003). The Status Of Environmental Education In Latin American Middle And High Schools. Paper Presented At The Annual Meeting Of The American Educational Research Association. Chicago, IL, 21-25 April.

Dominguez, L. A., \& Schilling, M. L. (2001). Environmental Awareness And Outdoor Recreation: A Pilot Program For People With Special Needs. World Leisure Journal, 43(3), 42-47. 
Dyment, J. (2005). Green School Grounds As Sites For Outdoor Learning: Barriers And Opportunities. International Research In Geographical And Environmental Education, 14(1), $28-45$.

Ekborg, M. (2003). How Student Teachers Use Scientific Conceptions To Discuss A Complex Environmental Issue. Journal Of Biological Education, 37(3), 126-132.

Ernst, J. (2007). Factors Associated With K-12 Teachers' Use Of Environment-Based Education. The Journal of Environmental Education, 38(3), 15-32.

Floridis, T. (2010). Remarks From The Participation Of Students With Disabilities In Environmental Education Programs Presentation Presented At The 5th Panhellenic Conference P.E.K.P.E. Entitled "Environmental Education: The Crossroads Of Education For Sustainable Development". Ioannina.

Giannopoulou, I., \& Kazakou, M. (2010). The Role Of Environmental Education In Special Education: The Example Of An Environmental Action In A Special School. Presentation Presented At The 5th Panhellenic Conference Of PEEKPE. Entitled "Environmental Education: The Crossroads Of Education For Sustainable Development". Ioannina. (pp. 26-28).

Gonzalez-Gaudiano, E. (2007). Schooling And Environment In Latin America In The Third Millennium. Environmental Education Research, 13(2), 155-169.

Gray, B. V. (1999). Guest Editorial: Science Education In The Developing World: Issues And Considerations. Journal of Research In Science Teaching, 36(3), 261-268.

Kellert, S. R. (2005). Building For Life: Designing And Understanding The Human-Nature Connection. Washington, DC: Island Press.

Kim, C., \& Fortner, R. W. (2006). Issue-Specific Barriers To Addressing Environmental Issues In The Classroom: An Exploratory Study. The Journal of Environmental Education, $37(3), 15-22$.

Ko, C., Lee, A. C., \& C, J. (2003). Teachers' Perceptions Of Teaching Environmental Issues Within The Science Curriculum: A Hong Kong Perspective. Journal Of Science Education And Technology, 12(3), 187-204.

Kollmuss, A., \& Agyeman, J. (2010). Mind The Gap: Why Do People Act Environmentally And What Are The Barriers To Pro- Environmental Behavior? Environmental Education Research, 8(3), 239-260.

Lappa, C., Kyparissos, N., \& Paraskevopoulos, S. (2017). Environmental Education At The Special School: Opinions Of Special Education Teachers. Natural Sciences Education(1), 4646.

Lee, J., Au, A., \& Ma, W. (2009). Progress Towards Education For Sustainable Development In Macao. In M. W. J. Lee (Ed.), Schooling For Sustainable Development In Chinese Communities. Springer.

Monroe, M., Scollo, G., \& Bowers, A. (2002). Assessing Teachers Needs For Environmental Education Services. Applied Environmental Education And Communication: An International Journal, 1(1), 37-43.

Moustakas, L., \& Fokiali, P. (2019). Motivation And Obstacles On Adult Participation In Lifelong Learning. A Statistical Approach. LAMBERT Academic Publication.

Muranen, J. (2014). The Importance Of Out-Of-School Environmental Education Entities For Integrating Environmental Education Into School Curriculum - Perspectives From Finnish And Dutch Environmental Education Experts [Master's Thesis]. School Of Management, Politics Of The Environment And Regions. University Of Tampere.

Papageorgiou, M., Kouravanas, G., Koutmanis, P., Angelis, K., \& Konstantinou, A. (2015). The Environmental Education Programs Of KPE Stylida - Ypatis As A Pedagogical Tool In 
Special Education. Proceedings Of The 7th Panhellenic Conference Of.

Papanis, E., Giavrimis, E., \& Viki, A. (2007). Special Education, Vocational Orientation of Persons With Disabilities And Deforestation. Mytilene: Agiasos-Lesvos Social Welfare Foundation "The Theomitor".

Penwell, R., Cronin-Jones, L., Hakverdi, M., Cline, S., \& Johnson, C. (2002). Teacher Perceptions Regarding The Status Of Environmental Education In Latin American Elementary Schools. Paper Presented At The American Educational Research Association. New Orleans, LA., 1-5.

Rickinson, M., Dillon, J., Teamey, K., Morris, M., Choi, M. Y., Sanders, D., \& Benefield. (2004). A Review Of Research On Outdoor Learning. National Foundation For Educational Research And King's College London.

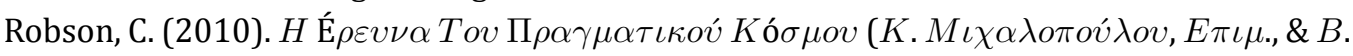

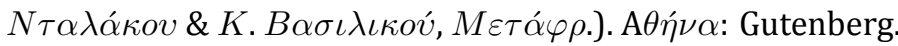

Sadik, F., \& Sadik, S. (2014). A Study On Environmental Knowledge And Attitudes Of Teacher Candidates. Procedia-Social And Behavioral Sciences, 116, 2379-2385.

Scruggs, T. E., \& Mastropieri, M. A. (1995). Science And Students With Mental Retardation: An Analysis Of Curriculum Features And Learners Characteristics. Science Education, $79(3), 251-271$.

Shiderman, R. (2016). Meeting Different Needs: Balancing Environmental And Special Education In Ontario's Elementary Classrooms. Retrieved from Https://Tspace.Library .Utoronto.Ca.

Simmons, D. (1998). Using Natural Settings For Environmental Education: Perceived Benefits And Barriers. Journal of Environmental Education, 29(3), 23-31.

Siperstein, G. N., Parker, R. C., Bardon, J. N., \& Widaman, K. F. (2007). A National Study Of Youth Attitudes Toward The Inclusion Of Students With Intellectual Disabilities. Exceptional Children, 73(4), 435-455.

Varnava, S., Polyzou, E., Skanavi, K., \& Papanis, E. (2009). Environmental Education And People With Disabilities. Presentation Presented At The SEP Scientific Conference. 